\title{
A Novel Soft-Switching Inverter Using Resonant Inductor Freewheeling
}

\author{
C.C. Chan, K.T. Chau, Jianming Yao, and D.T.W. Chan* \\ Department of Electrical \& Electronic Engineering, The University of Hong Kong, Pokfulam Road, Hong Kong \\ * Department of Electrical \& Communications Engineering, Hong Kong Technical College, Tsing Yi, Hong Kong
}

\begin{abstract}
A novel topology of the voltage-source softswitching inverter for induction motor drives is presented. The key of this topology is to employ two fractional-duty auxiliary switches and one resonant inductor per phase to provide a favorable zero-voltage turn-on condition for those main switches. By fully utilizing the inherent natural freewheeling of the inverter, the auxiliary switches need to operate in the resonant inductor freewheeling only in a fractional duty. Apart from providing the soft-switching environment with minimum voltage and current stresses, the distinct advantage of this topology is the capability to control the operation of each phase individually. Therefore, this inverter can readily adopt the well-established PWM techniques while possessing the advantages of soft switching - namely PWM-oriented soft switching. Moreover, a new concept of zero-voltage softswitching vector is introduced to determine whether the auxiliary circuit needs to operate for achieving soft switching. The theoretical analysis has been conducted and then verified by using both computer simulation and experimental results.
\end{abstract}

\section{Introduction}

Although the development of soft-switching inverters seems to be lagging behind that of dc-dc converters, a number of viable soft-switching inverter topologies have been proposed and discussed [1]-[18]. However, these softswitching inverters still have some problems to be tackled before widely acceptable for industrial applications.

The milestone of the development of soft-switching inverters is believed to be the resonant dc-link (RDCL) inverter which has been developed for over a decade [1]. It has been well known that its major drawback has been the high voltage or current stress. Although a modified version, namely the actively clamped resonant dc-link (ACRDCL) inverter, has overcome this fundamental drawback, the problems of overvoltage and relatively low reliability remain unsolved. Additionally, since all the corresponding inverter switches need to operate synchronously with the resonance of the dc link for achieving soft switching, both RDCL and ACRDCL inverters are incapable of using those well-established pulsewidth modulation (PWM) techniques.

By using auxiliary switches along with lossless resonant snubbers to achieve soft switching, various topologies of auxiliary resonant snubber based soft-switching inverters have been proposed [2]-[5]. In general, the parasitic inductance and stray capacitance of these inverters are utilized as a part of the resonant components, while there is no over-voltage or overcurrent penalty in the main inverter switches. Thus, these softswitching inverters potentially achieve high-efficiency power conversions in a cost-effective way of soft switching.
Nevertheless, they still have some problems which should be tackled before widely acceptable for industrial application.

According to their topologies and operating principles, three vital auxiliary resonant snubber based inverters are identified:

- auxiliary resonant commutated pole (ARCP) inverter;

- zero-voltage transition (ZVT) inverter;

- star/delta-configured auxiliary snubber (S/DCRS) inverter.

The ARCP inverter is one of the earliest auxiliary resonant snubber based inverters overcoming the drawbacks of those RDCL inverters [2]. It provides zero-voltage turn-on conditions without increasing the voltage and/or current stresses of the main switches. Moreover, individual phases can be modulated independently so that any PWM switching schemes can be realized. However, due to the presence of series capacitors across the dc link, voltage unbalancing may be resulted between those dc-link capacitors. Thus, it requires a stiff center-tapped dc-link capacitor bank to accomplish commutaton. Moreover, it requires voltage clamping devices to prevent over-voltage across those auxiliary switches.

The ZVT inverter follows the concept of ZVT in softswitching dc-dc converters [3]. Although this ZVT inverter takes the advantage of using only one auxiliary switch, it requires six ultra fast-recovery diodes to block the reverserecovery currents introduced in the resonant circuit, and voltage clamping devices to prevent over-voltage across the resonant switch. Besides, the corresponding three resonant branches need to operate simultaneously, and the inverter suffers from the difficulty in operating at the switching state of $(0,0,0)$ or $(1,1,1)$.

The SCRS and DCRS inverters are two recently developed versions of auxiliary resonant snubber based inverters [4], [5]. The DCRS inverter takes advantages over the SCRS version because it avoids a floating-point voltage which may cause over-voltage failure of the auxiliary switches, and there is no need to add anti-paralleled fast-recovery diodes across the resonant switches. However, the drawback is that at least two branches must operate simultaneously, limiting its versatility for various PWM switching schemes.

It should be noted that most of the soft-switching inverter topologies were proposed well before the development of the corresponding switching schemes, such as pulse density modulation and nonadjacent state space vector modulation. Even so, they introduce higher harmonic contamination than those well-established PWM schemes.

It is the purpose of this paper to introduce the concept of PWM-oriented soft switching so that the proposed softswitching inverter not only possesses the advantages of resonant snubber soft switching but also the capability of using those well-established PWM schemes. 


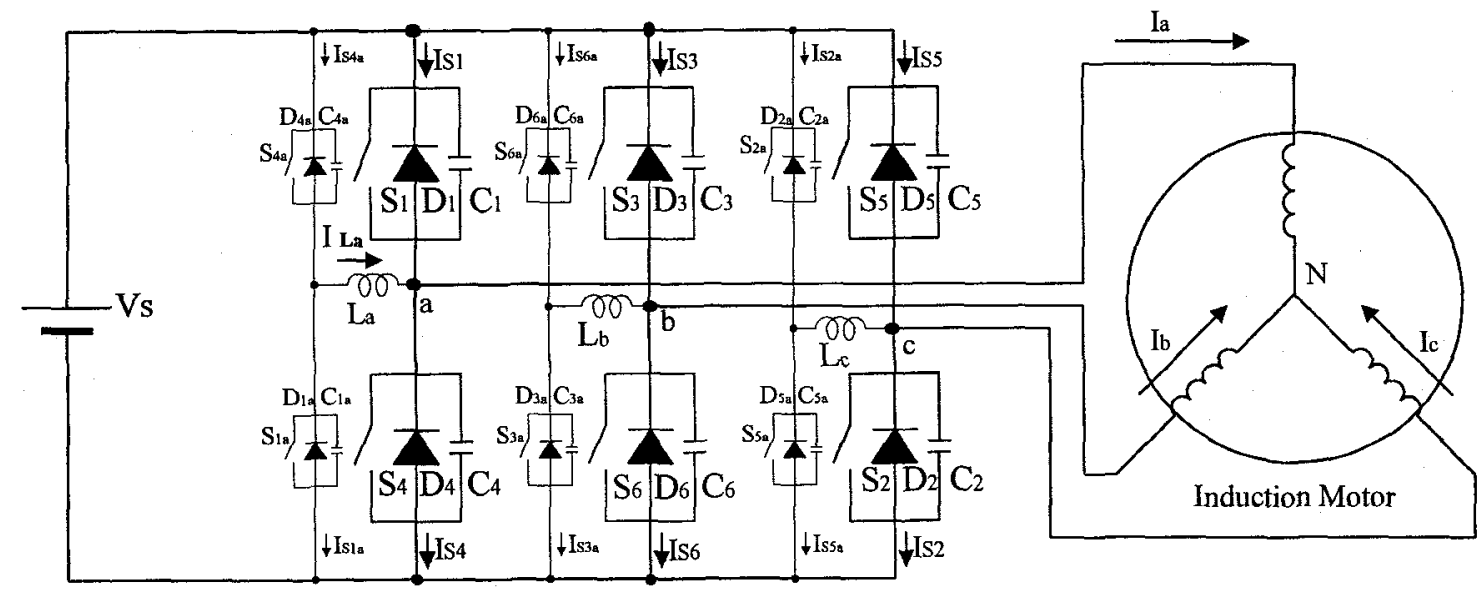

Fig. 1: Proposed inverter topology

\section{PWM-Oriented Soft Switching}

Our goals for the development of soft-switching inverters are set as follows:

- zero-voltage switching (ZVS);

- minimum voltage and/or current stresses;

- low $d v / d t$ and $d i / d t$

- flexible to adopt well-established PWM techniques.

To achieve these goals, a novel soft-switching inverter topology is generated by using the so-called PWM-oriented soft-switching approach. The proposed inverter feeding a three-phase induction motor is shown in Fig. 1.

\subsection{Natural freewheeling}

For hard-switching PWM schemes, there are four states corresponding to the combination of main switches within the same leg. Taking phase A for exemplification, these four states are:

State I S1 on and S4 off for $I_{a}>0$;

State II D1 on and S4 off for $I_{a}<0$;

State III S1 off and D4 on for $I_{a}>0$;

State IV S1 off and S4 on for $I_{a}<0$.

When $I_{\alpha}>0$, there are two possible cases for a change of the switching state between State I and State III. Similarly, when $I_{a}<0$, there are other two cases for a change between State II and State IV. Hence, the following four cases are defined as:

Case 1 State I to State III;

Case 2 State III to State I;

Case 3 State II to State IV;

Case 4 State IV to State II.

In Case $1, \mathrm{~S} 1$ is turned off first. Then, after an inserted period of dead time, S4 can be readily turned on at the ZVS condition because there is natural freewheeling via $\mathrm{D} 4$ after turning off S1. The problems are that the voltage across S1 rises to the dc-link voltage with high $d v / d t$ and may have an voltage overshoot caused by stray inductance. This turn-off $d v / d t$ can be significantly reduced by employing a turn-off snubber such as a capacitor across the switch while the voltage overshoot can also be reduced by adopting proper circuit layout and packaging.

In Case 2, $\mathrm{S} 4$ is subjected to turn off first but nothing takes place as the load current remains freewheeling via D4. After the preset dead time, $\mathrm{S} 1$ is turned on in the presence of full voltage, namely hard switching. At that instant, it forces the commutation of D4. However, due to the finite reverse recovery duration of $\mathrm{D} 4$, there is a temporary high reverse recovery current. Besides, there are also discharging and charging currents of the upper and lower snubber capacitors, respectively. Hence, the current $I_{s 1}$ through $\mathrm{S} 1$ for hardswitching turn on can be expressed as:

$$
I_{S 1}=I_{a}+I_{D 4 r}+I_{C 1}+I_{C 4}
$$

where $I_{a}$ is the load current in phase A, $I_{D 4 r}$ the reverse recovery current of $\mathrm{D} 4, I_{C 1}$ the discharging current of $\mathrm{Cl}$ and $I_{C 4}$ the charging current of $\mathrm{C} 4$.

In Case 3, the switches operate in the same mode as that of State III to State I. It is the inherent problem in a hardswitching inverter that there is a high reverse recovery current whenever a switch is turned on while the antiparallel diode of another switch is conducting.

In Case 4, the operation is similar to that of Case 1. Before turning on S1, the voltage across the S1 has already become zero due to the natural freewheeling via D1.

Therefore, by fully utilizing the inherent natural freewheeling process, resonant snubber assisted ZVS conditions are needed only when there are changes from State III to State I and from State II to State IV, namely the Case 2 and Case 3. Thus, the auxiliary switches of the proposed soft-switching inverter need to operate in the socalled resonant inductor freewheeling process only for short duration, so-called fractional duty. 


\subsection{Zero-voltage soft-switching vector}

Considering the widely accepted state space PWM switching scheme, there are eight state space vectors which correspond to eight inverter switching states:

$$
V_{i}=\left[\alpha_{a}, \alpha_{b}, \alpha_{c}\right]
$$

where $i=0,1,2, \ldots, 7$, and

$$
\alpha_{p}=\left\{\begin{array}{l}
0 \\
1
\end{array}\right.
$$

where $p=a, b, c$. The values of 0 and 1 represent the turn off and turn on of the upper switch, respectively. It should be noted that the on/off of the lower switch is always opposite to that of the upper one.

Since the direction of load current is important to determine whether the ZVS condition can be naturally achieved, the corresponding direction in phase $p$ is represented as:

$$
\beta_{p}=\operatorname{Sign}\left(I_{p}\right)
$$

where $\beta_{p}$ is +1 for $I_{p}>0$, and -1 for $I_{p}<0$. By changing $\beta_{p}$ into logic values to indicate the load current direction, $\gamma_{p}$ is written as:

$$
\gamma_{p}=\frac{1}{2}\left[1+\beta_{p}\right]=\frac{1}{2}\left[1+\operatorname{Sign}\left(I_{p}\right)\right]
$$

where $\gamma_{p}$ is 1 for $I_{p}>0$, and 0 when $I_{p}<0$.

In order to determine whether there is natural freewheeling or artificially resonant-inductor freewheeling, a concept of zero-voltage soft-switching vector (SSV) is newly defined as:

$$
S S V_{p}=\alpha_{p} \overline{\gamma_{p}}+\overline{\alpha_{p}} \gamma_{p}
$$

where $p=a, b, c$. Thus, $S S V_{p}=0$ indicates that there is natural freewheeling which provides the ZVS condition in the leg of phase $p$ without having any additional assistance from the auxiliary resonant snubber. On the contrary, for $S S V_{p}=1$, the auxiliary resonant snubber needs to perform resonant inductor freewheeling for achieving the desired ZVS condition. By employing the proposed SSV, the determination of natural or resonant inductor freewheeling in phase $\mathrm{A}$ is illustrated in Table 1 . It should be noted that this SSV can be easily generated by using simple hardware such as comparators and TTL chips. Furthermore, the corresponding zero-voltage,SSV for the three-phase inverter can then be represented as:

$$
S S V=\left[S S V_{a}, S S V_{b}, S S V_{c}\right]
$$

Table 1: SSV analysis in phase A

\begin{tabular}{|c|c|c|c|c|}
\hline & Case 1 & Case 2 & Case 3 & Case 4 \\
\hline ON Device & S1 & D4 & D1 & S4 \\
\hline OFF Device & S4 & S1 & S4 & S1 \\
\hline$I_{a}$ & Positive & Positive & Negative & Negative \\
\hline$\alpha_{a}$ & 1 & 0 & 1 & 0 \\
\hline$\beta_{p}$ & +1 & +1 & -1 & -1 \\
\hline$\gamma_{a}$ & 1 & 1 & 0 & 0 \\
\hline$S S V_{a}$ & 0 & 1 & 1 & 0 \\
\hline Natural & Yes & No & No & Yes \\
\hline Resonant & No & Yes & Yes & No \\
\hline
\end{tabular}

\section{Principle of Operation}

To illustrate the principle of operation of the proposed soft-switching inverter, especially so-called resonant inductor freewheeling, the Case 2 and Case 3 concerning respectively the change from State III to State I and State II to State IV are discussed. Both cases adopt phase A for exemplification.

\subsection{Case 2}

As shown in Fig. 2, there are six modes of operation:

- Mode $O\left(t<t_{0}\right)$ - It is equivalent to State III. The positive load current is freewheeling through $\mathrm{D} 4$, while S4 remains on and S1 off. In this mode of operation, $\alpha_{a}=0, \quad \gamma_{a}=\frac{1}{2}(1+1)=1$ and $S S V_{a}=0 \cdot \overline{1}+\overline{0} \cdot 1=1$. If there is a direct turn on of S1 to change the switching state of this phase, it will be a non-ZVS which also causes a high reverse recovery current spike due to the finite reverse recovery duration of D4. Thus, in order to overcome these problems, the use of an auxiliary switch $\mathrm{S} 4 \mathrm{a}$ in the following mode is necessary.

- Mode $1\left(t_{0} \sim t_{1}\right)-\mathrm{S} 4 \mathrm{a}$ is turned on. The current through D4 begins to decrease linearly as the current through the resonant inductor increases linearly. Taking the resonant inductor current as the state variable, the state equation and its solution are given by:

$$
\begin{aligned}
& V_{S}=L_{a} \frac{d I_{L a}}{d t} \\
& I_{L a}=\frac{V_{S}}{L_{a}}\left(t-t_{0}\right)
\end{aligned}
$$

- Mode $2\left(t_{1} \sim t_{2}\right)-$ At $t_{1}$, the current via D4 decreases to zero, when the resonant inductor current is equal to the load current. The current in S4 begins to increase. The resonant inductor current becomes greater than the load current as given by (9), and continues to rise until the stored energy is high enough to charge and discharge the snubber capacitors:

$$
L_{a}\left(I_{L a}-I_{a}\right)^{2} \geq\left(C_{1}+C_{4}+C_{1 a}+C_{4 a}\right) V_{s}^{2}
$$

- Mode $3\left(t_{2} \sim t_{3}\right)-$ After turning off both S4 and S4a, the snubber capacitors $\mathrm{Cl}$ and $\mathrm{Cla}$ begin to discharge to zero while $\mathrm{C} 4$ and $\mathrm{C} 4 \mathrm{a}$ begin to charge to full dc-link voltage. This is a resonance between the resonant inductor and the snubber capacitors $\mathrm{Cl}, \mathrm{C} 4, \mathrm{Cla}$ and $\mathrm{C} 4 \mathrm{a}$. Hence, the following equations are formulated:

$$
\begin{aligned}
& V_{1 a}+V_{4 a}=V_{s} \\
& V_{4 a}+L_{a} \frac{d I_{L a}}{d t}=V_{1} \\
& V_{1 a}-L_{a} \frac{d I_{L a}}{d t}=V_{4} \\
& C \frac{d V_{1}}{d t}+I_{L a}-I_{a}-C \frac{d V_{4}}{d t}=0 \\
& C \frac{d V_{4 a}}{d t}-I_{L a}-C \frac{d V_{1 a}}{d t}=0
\end{aligned}
$$

where $\mathrm{C}$ is the value of $\mathrm{Cl}, \mathrm{C4}, \mathrm{Cla}$ and $\mathrm{C} 4 \mathrm{a}$, and $\mathrm{V} 1$, $\mathrm{V} 4, \mathrm{Vla}$ and $\mathrm{V} 4 \mathrm{a}$ are respectively the voltage across $\mathrm{S} 1$, S2, S1a and S4a. 


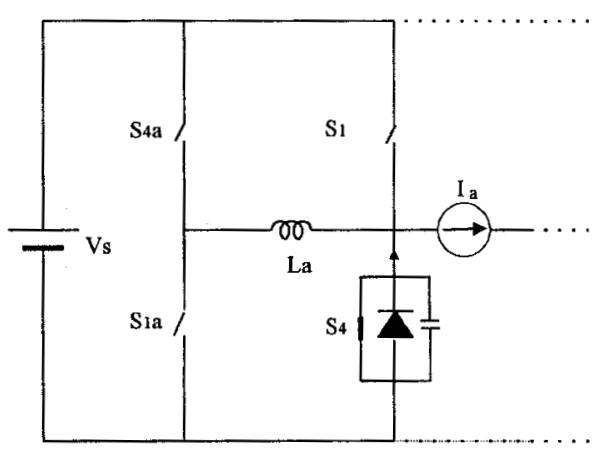

Mode 0

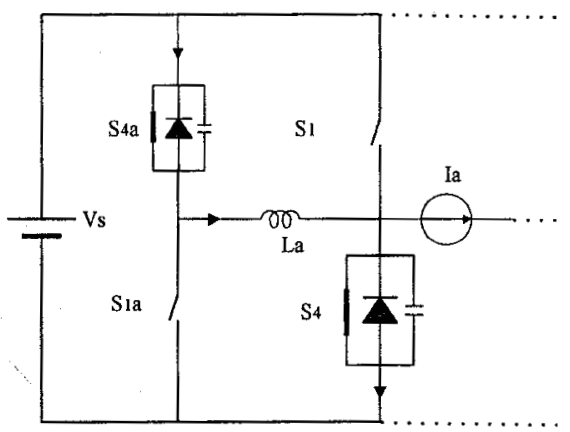

Mode 2

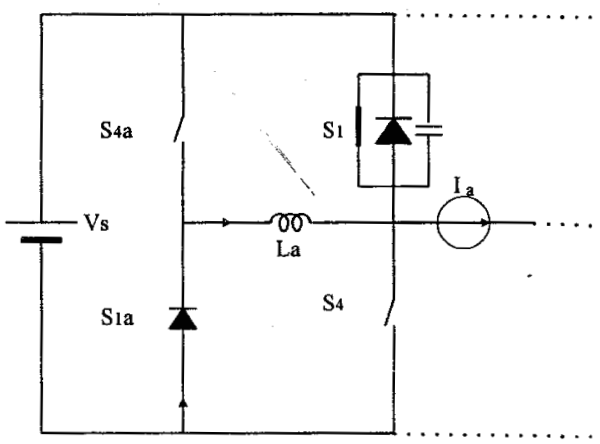

Mode 4

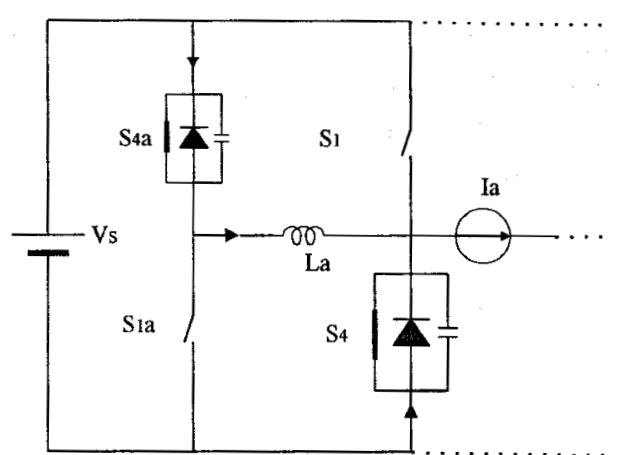

Mode 1

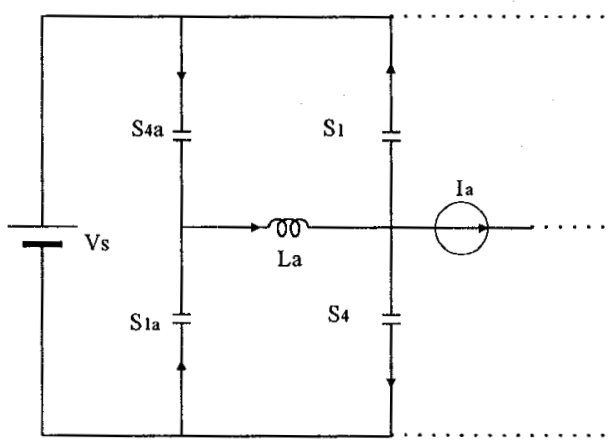

Mode 3

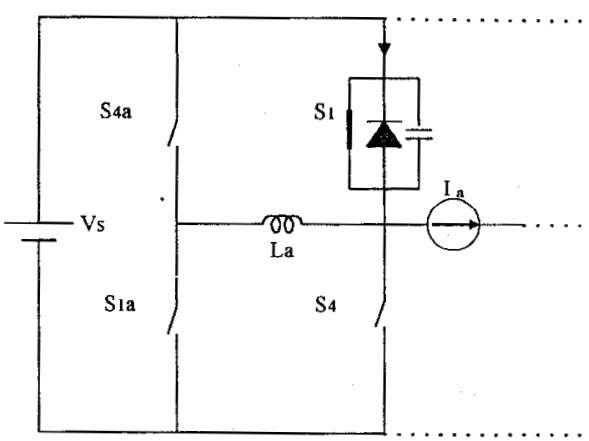

Mode 5

Fig. 2: Six modes of operation from State III to State I

Solving (11)-(15), the resonant inductor current can be written as:

$$
\begin{aligned}
& I_{L a}=A_{1} \cos \omega\left(t-t_{2}\right)+A_{2} \sin \omega\left(t-t_{2}\right)+\frac{1}{2} I_{a} \\
& A_{1}=I_{o}-\frac{I_{a}}{2}, A_{2}=\frac{V_{s}}{\omega L_{a}} \\
& \omega=\frac{1}{\sqrt{L_{a} C}} \\
& I_{0}=\frac{V_{s}}{L_{a}}\left(t_{2}-t_{0}\right)
\end{aligned}
$$

- Mode $4\left(t_{3} \sim t_{4}\right)$ - Because the resonant inductor current tends to keep unchanged, the so-called resonant inductor freewheeling is carried out via D1 and D1a. This current begins to decrease linearly as given by:

$$
I_{L_{a}}=I_{L_{a}}\left(t_{3}\right)-\frac{V_{x}}{L_{a}}\left(t-t_{3}\right)
$$

where $I_{L a}\left(t_{3}\right)$ can be obtained using (16). Meanwhile, $\mathrm{S} 1$ can be turned on at ZVS condition.
- Mode $5\left(t>t_{4}\right)$ - At $t_{4}$, the resonant inductor current becomes zero, and the load current is totally diverted to S1. It is the desired State I.

\subsection{Case 3}

The transition from State $I I$ to State $I V$ can be explained very similar to that from State III to State $I$. The corresponding six modes of operation are shown in Fig. 3 and briefly discussed as follows:

- Mode $0\left(t<t_{0}\right)$ - It is the State II.

- Mode $I\left(t_{0} \sim t_{1}\right)-\mathrm{S} 1 \mathrm{a}$ is turned on, and the resonant inductor current begins to increase linearly.

- Mode $2\left(t_{1} \sim t_{2}\right)$-. The resonant inductor current becomes greater than the load current.

- Mode $3\left(t_{2} \sim t_{3}\right)$ - After turning off both S1 and S1a, there is a resonance between the resonant inductor and snubber capacitors.

- Mode $4\left(t_{3} \sim t_{4}\right)$ - Resonant inductor freewheeling is carried out via D4 and D4a, so S4 can turn on at ZVS.

- Mode $5\left(t>t_{4}\right)$ It is the desired State IV. 


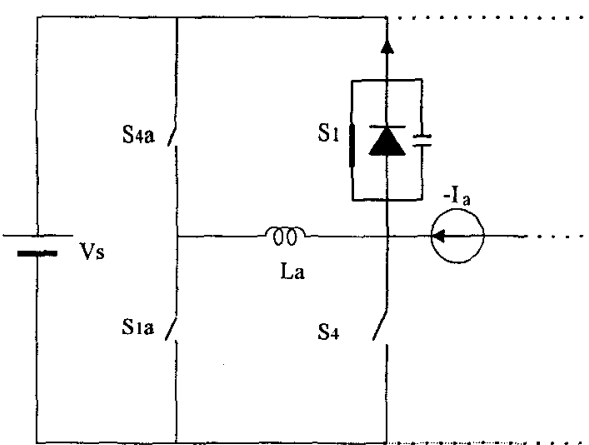

Mode 0

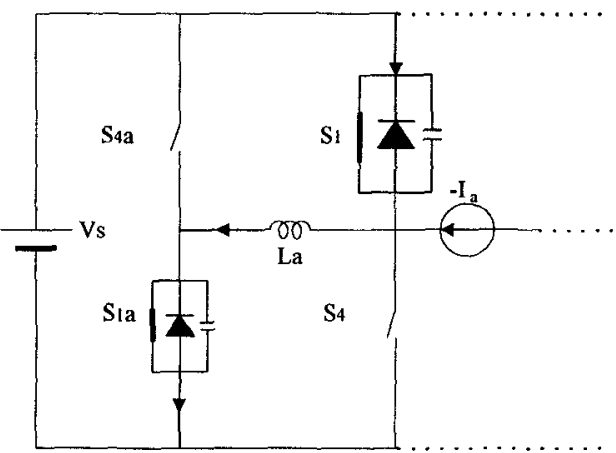

Mode 2

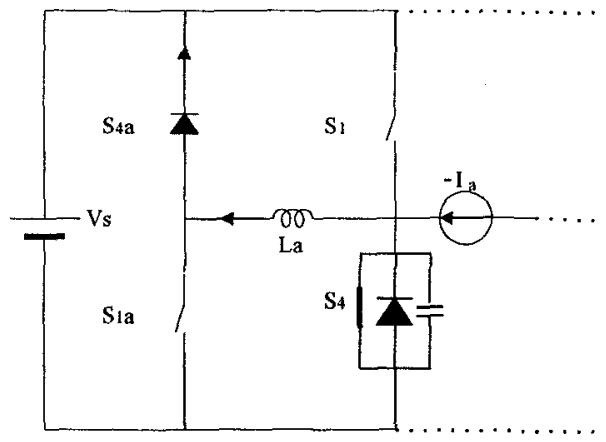

Mode 4

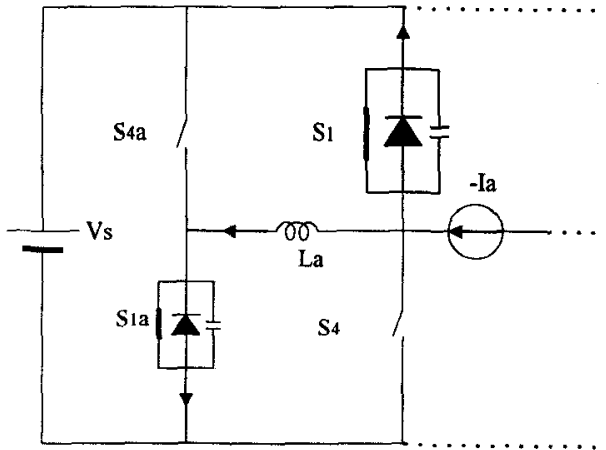

Mode 1

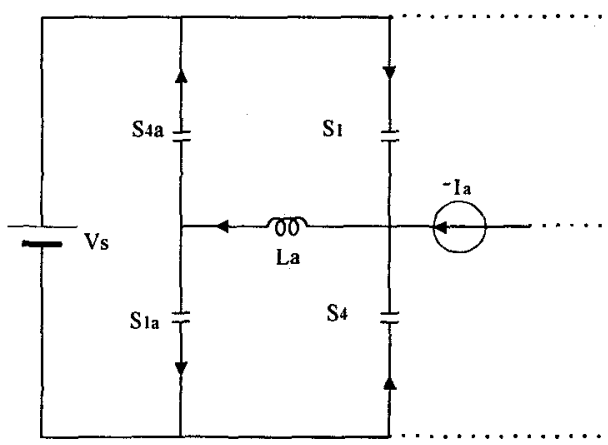

Mode 3

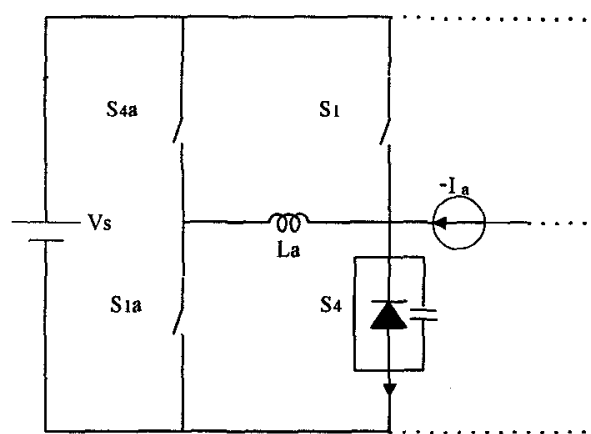

Mode 5

Fig. 3: Six modes of operation from State II to State IV

It should be noted that the aforementioned control of the switches in the leg for phase $\mathrm{A}$ is independent of any switches in other legs. Similar modes of operation can be found for the other phases, B and C. Therefore, all legs for three phases can be controlled independently, facilitating the adoption of any well-established PWM schemes.

\section{Simulation and Experimental Results}

Based on the derived equations, typical theoretical waveforms of the proposed soft-switching inverter can be obtained as shown in Fig. 4. By selecting practical component values and operating parameters, computer simulation of the proposed inverter can be carried out by using PSpice. As shown in Fig. 5, the PSpice simulation waveforms agree with those theoretical waveforms. Moreover, FFT analysis of the output load current is conducted. The corresponding spectrum, shown in Fig. 6, is very similar to that of the conventional hard-switching PWM inverter. It should be noted that most soft-switching inverters suffer from higher harmonic contamination than the conventional PWM inverter.

A prototype of the proposed soft-switching inverter is constructed with the main switches using Toshiba IGBT MG100H2YS1, auxiliary switches using IR Power MOSFET IRF740, resonant inductors of $5 \mu \mathrm{H}$ and polypropylene snubber capacitors of $47 \mathrm{nF}$.

The key of design is to determine the value of the snubber capacitors which can be calculated according to the desired $d v / d t$ value:

$$
C=I_{\text {Sot }} /\left(2\left(\frac{d v}{d t}\right)\right)
$$

where $I_{\text {saff }}$ is the maximum possible current flowing through the switch before being turned off. Once $\mathrm{C}$ - is obtained, the value of resonant inductor can be derived using (10).

Typical experimental waveforms are shown in Figs. 7, 8 and 9 which closely agree with both the theoretical and PSpice simulation waveforms. 


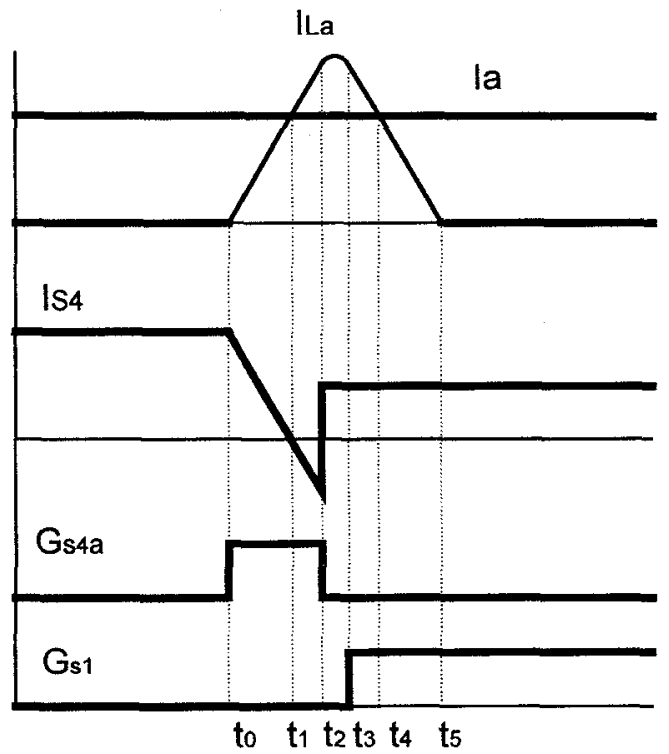

Fig 4: Theoretical waveforms

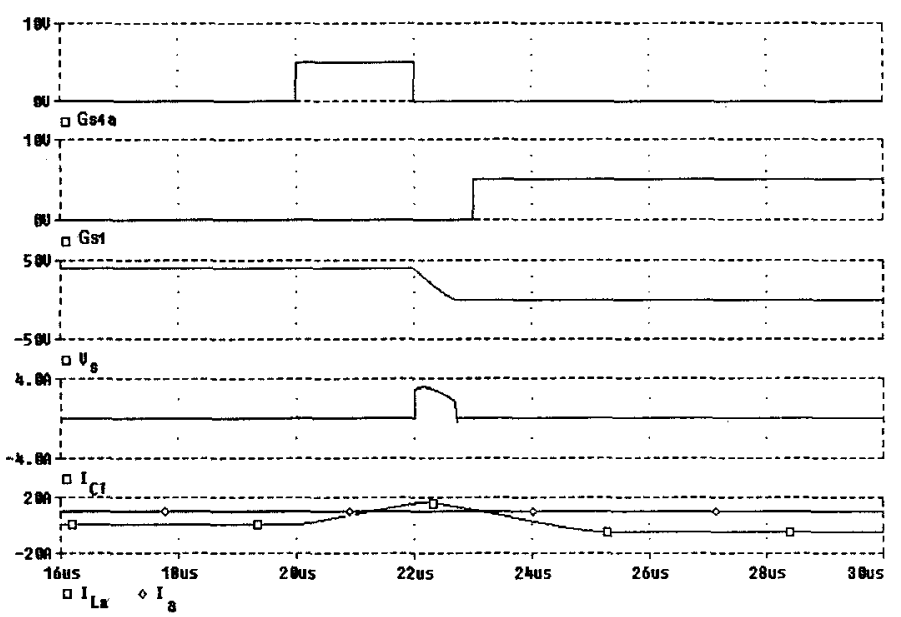

Fig 5: PSpice simulation waveforms

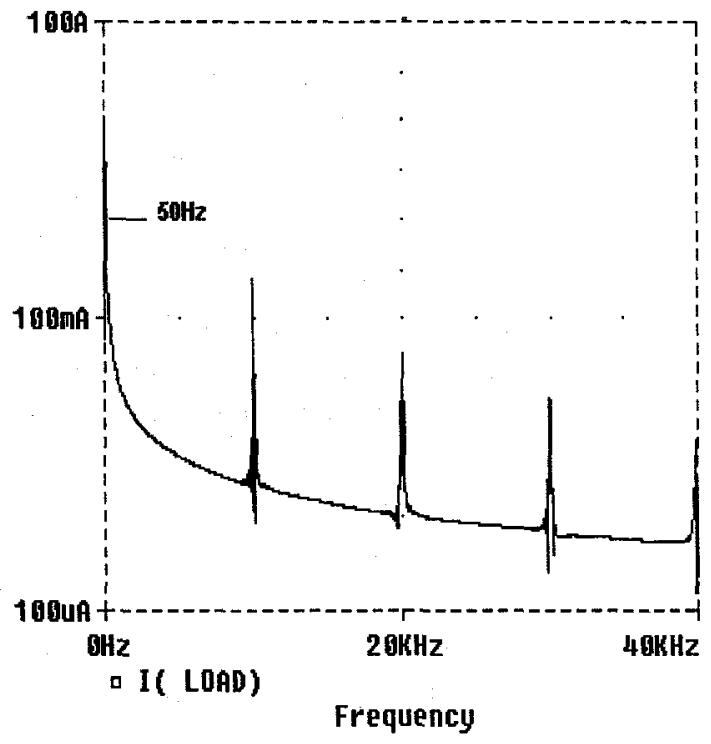

Fig. 6: Spectrum of load current

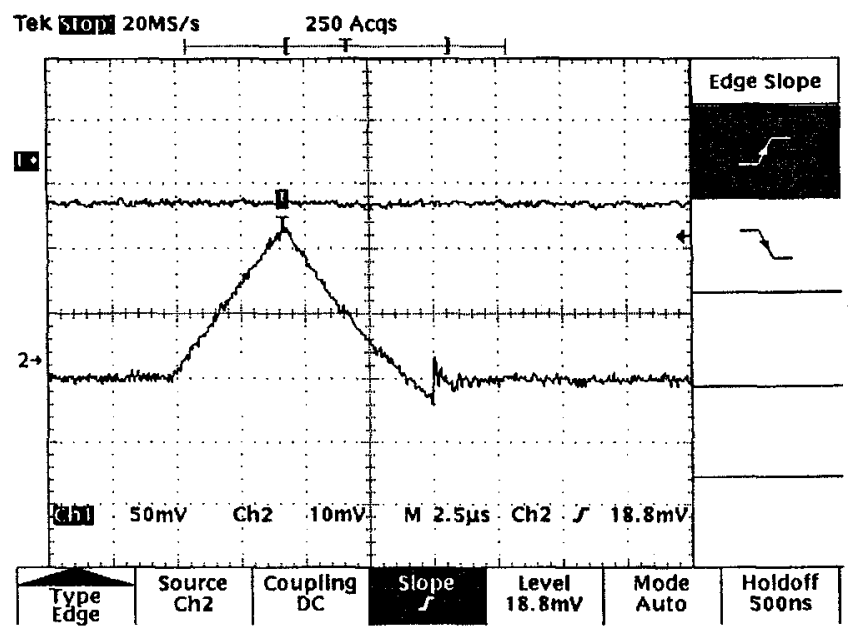

Fig. 7: Measured waveforms of

$I_{a}$ (upper trace) and $I_{L a}$ (lower trace)

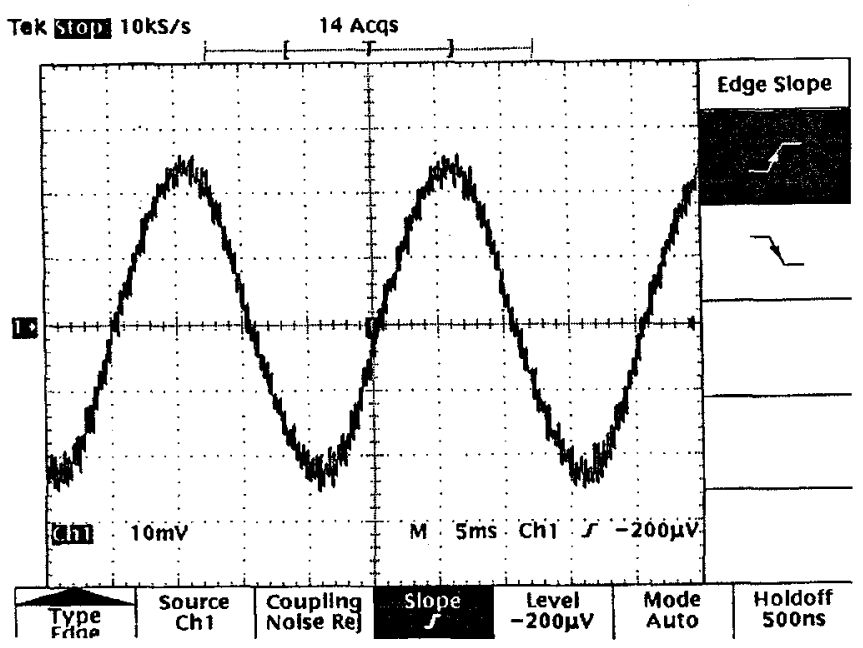

Fig. 8: Measured periodic waveform of $I_{a}$
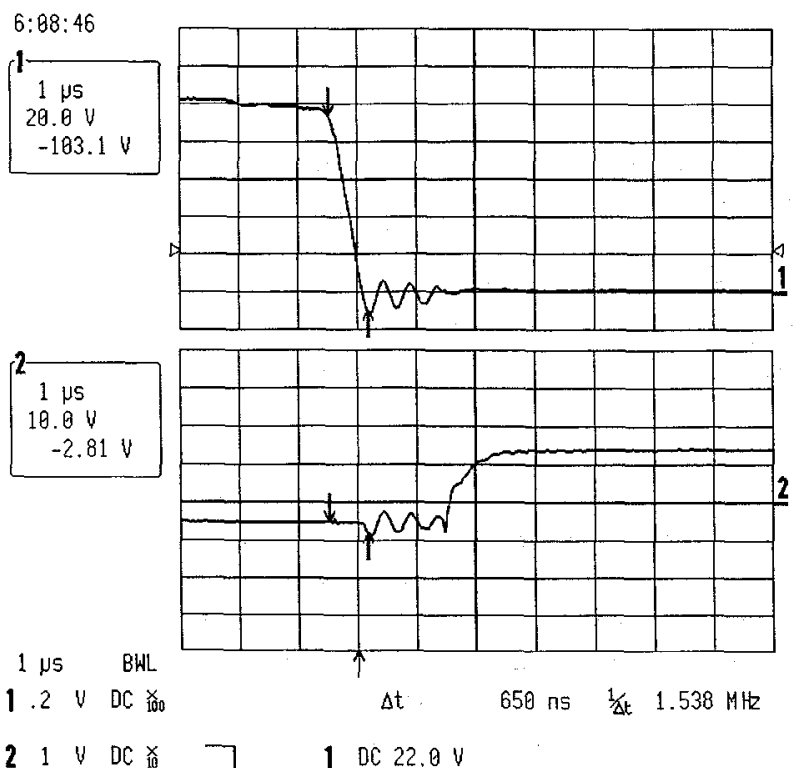

214 DC 希 $7 \quad 1$ DC $22.0 \mathrm{~V}$

Fig. 9: Measured waveforms of

$V_{d s}$ (upper trace) and $V_{g s}$ (lower trace) for ZVS 


\section{Conclusions}

A novel topology of the voltage-source soft-switching inverter for induction motor drives has been presented. By analyzing the transition of switching states for those conventional hard-switching PWM inverters, the so-called zero-voltage soft-switching vector is newly introduced to determine whether natural freewheeling occurs or the resonant inductor freewheeling is performed. The proposed soft-switching inverter not only possesses the advantages of soft switching and minimum voltage/current stresses, but also the capability to control the operation of each phase independently. The main switches of the inverter always work at the ZVS condition while the auxiliary switches are generally of fractional duty and low capacity compared to that for the main switches. The independent control of all three phases facilitates the inverter to adopt any wellestablished PWM switching schemes such as state space vector PWM.

\section{Acknowledgment}

This work was supported and funded in part by the Committee on Research and Conference Grants, the University of Hong Kong.

\section{References}

[1] D.M. Divan, "Resonant dc link converter - a new concept in static power conversion", In Proceedings of the IEEE Industry Applications Society Annual Meeting, 1986, pp. 648-656

[2] R.W. DeDoncker and J.P. Lyons, "The auxiliary quasiresonant dc link inverter", In Proceedings of the IEEE Power Electronics Specialists Conference, 1991, pp. 248-253

[3] V. Vlatkovic, D. Borojevic, F.C. Lee, C. Cuadros and S. Gataric, "A new zero-voltage transition, three-phase PWM rectifier/inverter circuit", In Proceedings of the IEEE Power Electronics Specialists Conference, 1993, pp. 868-873

[4] J.S. Lai, R.W. Young, Sr., G.W. Ott, Jr, C.P. White, J.W. McKeever and D.S. Chen, "A novel resonant snubber inverter", In Proceedings of the IEEE Applied Power Electronics Conference and Exposition, 1995 pp. 797-803

[5] J.S. Lai, R.W. Young, Sr., G.W. Ott, Jr., J.W. McKeever and F.Z. Peng, "A delta-configured auxiliary resonant snubber inverter", IEEE Transactions on Industrial Applications, vol. 32, no. 3, 1996, pp. 518-525

[6] J.S. Lai, R.W. Young, J.W. McKeever, "Efficiency consideration of DC link soft-switching inverters for motor drive applications", In Proceedings of the IEEE Power Electronics Specialists Conference, 1994, pp. 1003-1010
[7] V. Vlatkovic, D. Borojevic and F.C. Lee, "Softtransition three-phase PWM conversion technology", In Proceedings of the IEEE Power Electronics Specialists Conference, 1994, pp. 79-84

[8] S. Chen and T.A. Lipo, "Soft-switched inverter for electric vehicle drives", In Proceedings of the IEEE Applied Power Electronics Conference and Exposition, 1995, pp. 586-591

[9] S. Chen and T.A. Lipo, "Passively clamped quasi resonant DC link inverter", In Proceedings of the IEEE Industry Applications Society Annual Meeting, 1994, pp. 841-848

[10] S.G. Abeyratne, M.T. Aydemir, T.A. Lipo, Y. Murai and M. Yoshida, "Current clamped, PWM, quasiresonant DC link series resonant converter", In Proceedings of the IEEE Industry Applications Society Annual Meeting, 1994, pp. 820-826

[11] Y. Murai, H. Ishikawa, T.A. Lipo, "New series resonant DC link inverter for electric vehicle drives", In Proceedings of the IEEE Industry Applications Society Annual Meeting, 1994, pp. 443-447

[12] S. Bhattacharya, L. Resta, D.M. Divan, D.W. Novotny and T.A. Lipo, "Experimental comparison of motor bearing currents with PWM hard and soft switched voltage source inverters", In Proceedings of the IEEE Power Electronics Specialists Conference, 1996, pp. 1528-1534

[13] A. Julian, D.M. Divan, T.A. Lipo, F. Nozari and P.A. Mezs, "Double bridge resonant DC link converter with variable input and output frequency", In Proceedings of the IEEE Applied Power Electronics Conference and Exposition, 1996, pp. 181-186

[14] J.S. Lai, "Practical design methodology of auxiliary resonant snubber inverters", In Proceedings of the IEEE Power Electronics Specialists Conference, 1996, pp. $432-437$

[15] J.S. Lai, R.W. Young, Sr., G.W. Ott and J.W. McKeever, "Efficiency modeling and evaluation of a resonant snubber based soft-switching inverter for motor drive applications", In Proceedings of the IEEE Power Electronics Specialists Conference, 1995, pp. 943-949

[16] S. Chen and T.A. Lipo, "Novel soft-switched PWM inverter for AC motor drives", IEEE Transactions on Power Electronics, vol. 11, no: 4, 1996, pp. 653-659

[17] S. Chen, F. Cardoso, J. Braz and T.A. Lipo, "Design and implementation of a passively clamped quasi resonant DC link inverter', In Proceedings of the IEEE Industry Applications Society Annual Meeting, 1995, pp. 2387-2392

[18] J.S. Lai, "Resonant snubber based soft-switching inverters for electric propulsion drives", IEEE Transactions on Industrial Electronics, vol. 44, no. 1, 1997 